\title{
Efeitos do programa de microcrédito rural Agroamigo sobre a sustentabilidade dos agricultores familiares no município de Jardim, Ceará
}

\author{
Sergio Erlane Santos Silva ${ }^{1}$ \\ Eliane Pinheiro de Sousa ${ }^{2}$
}

Resumo: O microcrédito rural Agroamigo exerce papel fundamental para o financiamento da atividade agropecuária local e inclusão social dos pequenos produtores rurais. Diante dessa relevância, esta pesquisa busca analisar os efeitos desse programa sobre a sustentabilidade dos agricultores familiares no município de Jardim, Ceará. A natureza dos dados foi obtida por meio de informações primárias, mediante aplicação de questionários com 66 beneficiários e 66 não beneficiários. Para definir o Índice de Sustentabilidade (IS), foram considerados quatro índices: Índice de Desenvolvimento Econômico Social (IDES), Índice de Capital Social (ICS), Índice de Desenvolvimento Ambiental (IDA) e Índice Político-Institucional (IPI). Os resultados mostraram que o IDES foi o que teve mais representatividade, com maior destaque para os indicadores Habitação e Econômico, e menos expressivo para o indicador Educação. Em contrapartida, o IDA é o que tem causado maiores preocupações nos dois grupos analisados. Ressalta-se que os beneficiários possuem uma superioridade em relação aos não beneficiários, no que tange aos resultados obtidos pelo ICS e IPI.

Palavras-chave: Agroamigo. Sustentabilidade. Agricultura familiar.

\begin{abstract}
The rural microcredit Agroamigo has a fundamental role to finance the local agricultural activity and social inclusion of small rural producers. Given this relevance, this research seeks to analyze the effects of microcredit program on rural Agroamigo on the sustainability of family farmers in the municipality of Jardim, Ceará. The nature of the data was obtained by means of primary information, acquired by applying questionnaires with 66 beneficiaries and 66 non-beneficiaries. To define the Sustainability Index (IS), were considered four indexes: Economic Social Development Index (IDES), Social Capital Index (ICS), Environmental Development Index (IDA) and Political-Institutional Index (IPI). The results showed that's what IDES demonstrated more representativeness, with greater emphasis on Housing and Economic indicators, and less expressive for the Education indicator. On the other hand, the IDA is what has caused concerns in both groups. It should be noted that the beneficiaries have superiority in relation to non-beneficiaries with regard to results obtained by ICS and IPI.
\end{abstract}

Keywords: Agroamigo. Sustainability. Family agriculture.

\footnotetext{
${ }^{1}$ Economista pela Universidade Regional do Cariri (URCA). E-mail: sergioerlane.se@gmail.com.

2 Pós-Doutora em Economia Aplicada pela Escola Superior de Agricultura Luiz de Queiroz da Universidade de São Paulo (ESALQ/USP). Doutora em Economia Aplicada pela Universidade Federal de Viçosa (UFV) e Professora Associada do Departamento de Economia da Universidade Regional do Cariri (URCA). E-mail: pinheiroeliane@hotmail.com.
} 


\section{Introdução}

A agricultura familiar é uma das responsáveis pela alimentação do mundo, mas, para isso, são necessários recursos naturais para suprir a demanda, que se concentra em grandes quantidades. Portanto, nota-se a importância de se produzir de forma sustentável, visto que as práticas agrícolas utilizadas comprometem consideravelmente o meio ambiente (SANTOS; CÂNDIDO, 2013).

Segundo Rosseti (2013), o desenvolvimento rural vem diminuindo, especialmente na agricultura familiar, em função do êxodo rural, no qual muitas famílias deixam o campo por uma perspectiva de melhoria de vida na cidade. Como consequência, há uma redução da população rural e uma substancial elevação do número de pessoas na cidade. Uma forma de contribuição para o êxodo rural tem sido a introdução das tecnologias na agricultura, porém muitas famílias não dispõem de condições financeiras suficientes para financiar a compra do maquinário necessário. Neste contexto, surge a necessidade de algum incentivo ou fomento ao agricultor familiar, para que o mesmo possa desenvolver suas atividades e contribuir com a geração de emprego e renda aliado a uma produção sustentável.

Atualmente existe o Programa Nacional de Fortalecimento da Agricultura Familiar (PRONAF), que busca estimular a geração de renda e melhorar a mão de obra familiar mediante o financiamento de atividades rurais agropecuárias e não agropecuárias desenvolvidas em estabelecimentos rurais ou em áreas próximas (BACEN, 2015).

Outro fator incentivador ao agricultor familiar é o Agroamigo do Banco do Nordeste. Esse programa se dá por meio da concessão de crédito e busca melhorar o perfil socioeconômico do agricultor familiar, impulsionar a sustentabilidade dos empreendimentos rurais, propiciar a igualdade de gênero no campo e a redução de desigualdades. Destina-se aos agricultores familiares enquadrados no PRONAF, em operações até $\mathrm{R} \$ 15$ mil, limite para uma operação nas modalidades: Agroamigo Crescer (para agricultores enquadrados no grupo B do PRONAF) e Agroamigo Mais (para agricultores que fazem parte dos demais grupos do PRONAF, exceto A e A/C. Além dessas, tem-se também o Agroamigo Sol, que visa financiar a implantação de sistemas de micro e minigeração de energia solar e outras fontes renováveis (BANCO DO NORDESTE, 2019).

Dados do Banco do Nordeste (2019) revelam que, em julho de 2019, registrou-se uma aplicação de mais de $\mathrm{R} \$ 16,2$ bilhões comparativamente à sua criação, compreendendo 4,35 milhões de operações contratadas. Com uma carteira ativa de $\mathrm{R} \$ 4,58$ bilhões, o Agroamigo conta com mais de 1,26 milhões de clientes ativos distribuídos no Nordeste brasileiro e Norte de Minas Gerais e Espírito Santo.

No município de Jardim, Ceará, área de estudo desta pesquisa, não é diferente. O Agroamigo contribui com a geração de emprego e renda, pelo fato de haver diversos agricultores familiares beneficiários que investem em agricultura, pecuária, piscicultura, artesanato etc. De acordo com entrevista realizada com Nascimento (2017), antes da inserção do Agroamigo no município de Jardim, Ceará, a produção agrícola era concentrada em grandes produtores de milho e arroz. Após a implementação deste programa, é notória a inclusão social dos agricultores familiares na geração de emprego e renda no município, sendo um dos responsáveis pelo abastecimento de alguns mercados tradicionais e feiras livres. 
Diante dessas considerações, verifica-se que o Agroamigo exerce papel fundamental para o financiamento da atividade agropecuária local e inclusão social dos pequenos produtores rurais. Tendo em vista que muitos agricultores não possuem condições financeiras suficientes para custear o seu negócio, esse tema reveste-se de importância, como forma de trazer uma visão minuciosa dos efeitos que o programa Agroamigo gera na sustentabilidade social, econômica, ambiental e institucional dos agricultores familiares do município de Jardim, Ceará, contribuindo em termos de estratégias políticas.

Segundo Sachs (2008), o conceito de sustentabilidade deve considerar essas múltiplas dimensões, em que se trabalham, em conjunto, uma complementando a outra. Caso contrário, incorre-se no risco da parcialidade. Alves e Bastos (2011) corroboram que a sustentabilidade contempla tais aspectos na determinação do perfil da agricultura familiar e suas especificidades locais.

Portanto, este estudo se propõe analisar os efeitos deste programa sobre a sustentabilidade social, econômica, ambiental e institucional dos agricultores familiares em Jardim, Ceará.

Além dessa seção introdutória, o artigo está estruturado em quatro seções. A segunda aborda a revisão bibliográfica, em que se faz um breve panorama do microcrédito no Brasil e a implantação do Agroamigo, são mostrados os principais efeitos desse programa para os beneficiários conforme a literatura, assim como evidências empíricas sobre tal programa. Em seguida, são descritos a área de estudo, a natureza dos dados, a determinação do tamanho da amostra e os métodos analíticos. A próxima é destinada à apresentação e discussão dos resultados e reserva-se a última seção para as considerações finais.

\section{Revisão bibliográfica}

\section{Panorama do microcrédito no Brasil e implantação do Agroamigo}

A primeira experiência em microcrédito no Brasil foi desenvolvida pela União Nordestina de Assistência a Pequenas Organizações em Recife (PE) e Salvador (BA) e funcionou de 1973 a 1991. Os primeiros programas públicos destinados ao microcrédito surgiram na década de 1990, sendo que, em 1996, o BNDES criou o Programa de Crédito Produtivo Popular, que visava fornecer funding para organizações da sociedade civil especializadas em microcrédito. Em 1997, o Banco do Nordeste (BNB) lançou o Programa Crediamigo (BNDES, 2016).

Para Gonzalez, Porto e Diniz (2017), a evolução do microcrédito no Brasil foi fortemente condicionada à atuação do setor público, com destaque para o Programa Crediamigo. Em 1999, foi proposto ao Banco do Nordeste o desafio do Agroamigo atender agricultores do grupo B, que estavam abaixo da linha da pobreza com rendimento até $\mathrm{R} \$ 4$ mil por ano e que não tinham acesso ao crédito bancário. O Banco do Nordeste foi o primeiro a trabalhar com esse público, porém, como não havia monitoramento apropriado, a inadimplência chegou a 40\%. Com a implementação do microcrédito orientado, atualmente a inadimplência está em torno de $2 \%$, embora tenha enfrentado a pior seca dos últimos 50 anos.

Com base no Quadro 1, percebe-se que as operações contratadas do "Agroamigo Crescer" se alocam, em maior parte, de $\mathrm{R} \$ 3.001,00$ a $\mathrm{R} \$ 4.000,00$, representando 34\% do total de operações, ao passo 
que apenas 4\% utilizam valores até R\$ 1.000,00 durante o período de 2005 a julho de 2019. Em relação ao “Agroamigo Mais”, desde 2005 a julho de 2019, está explicita a preferência por parte dos agricultores, por valores de $\mathrm{R} \$ 10.001,00$ a $\mathrm{R} \$ 15.000,00$, correspondendo 71,8\% das operações realizadas, enquanto apenas $2 \%$ dos agricultores optam por valores até $\mathrm{R} \$ 2.500,00$.

Quadro 1 - Participação relativa das quantidades de operações contratadas acumuladas, por faixa de valor, destinadas aos públicos do Agroamigo Crescer e do Agroamigo Mais

\begin{tabular}{|c|c|c|c|}
\hline \multicolumn{2}{|c|}{ Agroamigo Crescer* } & \multicolumn{2}{|c|}{ Agroamigo Mais** } \\
\hline $\begin{array}{c}\text { Faixas de valor } \\
\text { (em } \mathrm{R} \$ \text { ) }\end{array}$ & $\begin{array}{c}\text { Frequência relativa } \\
(\%)\end{array}$ & $\begin{array}{c}\text { Faixas de valor } \\
(\text { em } \mathrm{R} \$)\end{array}$ & $\begin{array}{c}\text { Frequência relativa } \\
(\%)\end{array}$ \\
\hline Até 1.000 & 4,0 & Até 2.500 & 2,0 \\
\hline De 1.001 a 2.000 & 25,0 & De 2.501 a 5.000 & 7,4 \\
\hline De 2.001 a 3.000 & 19,0 & De 5.001 a 10.000 & 18,7 \\
\hline De 3.001 a 4.000 & 34,0 & \multirow[t]{2}{*}{ De 10.001 a 15.000} & \multirow[t]{2}{*}{71,8} \\
\hline De 4.001 a 5.000 & 18,0 & & \\
\hline
\end{tabular}

Fonte: Elaborado pelos autores, a partir dos dados do Banco do Nordeste (2019).

Nota: * Referente ao período de 2005 a julho de 2019; ** referente ao período de 2012 a julho de 2019.

\section{Principais efeitos do Agroamigo para os seus beneficiários}

O Agroamigo atua de forma não apenas visando disponibilizar créditos, mas também busca aderir aos Objetivos de Desenvolvimento Sustentável (ODS), como erradicação da pobreza, fome zero e agricultura sustentável, igualdade de gênero, trabalho decente e crescimento econômico, redução das desigualdades, consumo e produção responsáveis (BANCO DO NORDESTE, 2019).

Dentre as formas de combate à pobreza, o microcrédito, em especial, o Agroamigo, é visto como uma ferramenta importante por disponibilizar financiamentos que serão investidos no processo produtivo, alavancando, assim, suas atividades iniciais e proporcionando uma lucratividade ascendente para os produtores (DUARTE, COSTA; ARAUJO, 2017). Para esses autores, o Agroamigo tem impacto positivo sobre o volume de pessoas pobres na região Nordeste e constatam que essa política é eficaz para reduzir a pobreza na região. Ressalvam ainda a importância de políticas públicas de acesso ao crédito, voltado aos mais necessitados, contribuindo para inclusão destes no mercado financeiro, não apenas com a concessão de créditos, mas também com oportunidades de abertura de contas, adesão a seguros, cartões de créditos entre outros serviços bancários que geralmente é restrito a esta população.

Analisando variáveis socioeconômicas no combate à pobreza, Abramovay et al. (2013) notam que aqueles com mais operações junto ao Agroamigo dispõem de mais oportunidades em mercados agropecuários, facilitando, assim, o próprio desenvolvimento. Para Maciel et al. (2009), em estudo realizado com beneficiários e não beneficiários em Quixadá - CE, constataram que a renda de grande parte dos beneficiários é advinda da agricultura, enquanto a dos não beneficiários provém de pensões e aposentadorias, mostrando que o programa tem contribuído para o desenvolvimento de atividades produtivas no campo/agricultura.

A melhoria das condições de vida dos beneficiários do Agroamigo também é verificada por Cruz (2012). Em seu estudo realizado em Caruaru - PE, quase todos os beneficiários entrevistados mostraram- 
se satisfeitos quanto ao programa e reconheceram que o Agroamigo permitiu uma substancial melhoria nos seus negócios financeiros. Comparando os agropecuaristas e não agropecuaristas pesquisados, notouse que os não agropecuaristas preferem reinvestir o lucro auferido após o investimento realizado por intermédio do Agroamigo na mesma atividade, enquanto os agropecuaristas optam por reformar sua casa, indicando que a moradia é um fator essencial para a qualidade de vida dessas pessoas.

Assim como a moradia, Maciel et al. (2009) destacam outros fatores que são primordiais para uma melhoria na qualidade de vida dos beneficiários do Agroamigo. A educação, por exemplo, permite ao indivíduo acumular maiores conhecimentos, tornando-o mais qualificado e menos vulnerável ao desemprego. A saúde, por sua vez, impacta na geração de rendimentos, haja vista que indivíduos que tenham uma probabilidade maior de adoecer acabam se tornando mais pobres, agravando a distribuição de renda.

Segundo Vasconcelos (2014), para que haja uma boa qualidade de vida, é necessário dispor de saúde que não comprometa suas atividades diárias, emprego que seja suficiente para garantir o sustento da família, lazer em proximidade a suas residências e obter bens de consumo. Ademais, destaca-se que as condições sanitárias e de higiene e a educação também são fundamentais para se analisar a qualidade de vida dos beneficiários do Agroamigo.

Além de interesses sociais e econômicos, o Agroamigo busca disseminar a importância da utilização sustentável dos recursos naturais, em função da visão sob a preservação do meio ambiente e da utilização de métodos de produção menos agressivos à natureza (BANCO DO NORDESTE, 2015).

\section{Evidências empíricas sobre o Programa Agroamigo}

Em face da relevância do programa Agroamigo, pesquisas empíricas têm sido realizadas em diferentes áreas de estudo. Dentre essas, pode-se citar os trabalhos de Maciel et al. (2009); Maciel (2009); Neri (2012); Vasconcelos (2014); Nunes et al. (2015); Aquino e Bastos (2015); Duarte, Costa e Araujo (2017); e Duarte et al. (2018).

Maciel et al. (2009) estudaram o impacto do Agroamigo na melhoria das condições das famílias beneficiadas no Ceará. Para tal, consideraram como estudo de caso o município de Quixadá. Utilizaram análises tabular, descritiva e gráfica, e testes T-Student, Tukey e Kruskall-Wallis para, respectivamente, comparação das médias e proporções. A pesquisa foi realizada com 15 não beneficiários e 45 beneficiários em 2008. Os resultados mostraram que a maior participação relativa de beneficiários (82,3\%) e não beneficiários (66,6\%) encontra-se no nível médio de qualidade de vida, sendo que as maiores contribuições vieram das condições de moradia, educação e saúde, enquanto o lazer foi o que menos contribuiu.

Maciel (2009) investigou a contribuição do Agroamigo para a melhoria do processo de operacionalização do PRONAF, sob a ótica dos beneficiários e mediadores desta política. As questões inerentes às condições de vida dos beneficiários do programa e a sua capacidade de organização e mobilização na comunidade em que vivem também foram analisadas. Para isso, realizou-se pesquisa junto a 41 famílias que obtiveram financiamento tanto por meio do PRONAF B convencional quanto através 
de operações pelo Agroamigo no município cearense de Caucaia, em 2008. Verificou-se que a adoção da metodologia apropriada de microcrédito e a especialização do assessor de crédito possibilitaram a melhoria do atendimento e do financiamento tanto em termos qualitativos como quantitativos.

Neri (2012) buscou analisar o desempenho dos beneficiários do Agroamigo, considerando duas amostras de clientes em dois períodos de tempo, totalizando quase 73 mil clientes. Os resultados apontaram que, em geral, o lucro dos clientes registrou um aumento médio expressivo quando se compara o primeiro ano com o segundo, sendo que os maiores lucros obtidos no momento final da análise foram verificados nos estados do Maranhão, Alagoas e Bahia, enquanto os menores lucros foram encontrados no Ceará e na Paraíba.

Vasconcelos (2014) analisou o Agroamigo em Rio Tinto - PB e seus possíveis impactos na renda e na melhoria das condições de vida das famílias beneficiadas. Para tal, 60 agricultores foram entrevistados nos primeiros semestres de 2013 e 2014. Os métodos utilizados foram a comparação de médias (teste TStudent) e análises tabular e descritiva. Os dados mostraram que a renda média dos entrevistados teve uma elevação substancial, passando de $\mathrm{R} \$ 1.005,48$, em 2013, para $\mathrm{R} \$ 4.651,51$, em 2014, possibilitando a aquisição de bens duráveis. Esse resultado está consistente com os estudos de Maciel et al. (2009) e Cruz (2012). Outro fator importante foi o aumento médio da área dos imóveis rurais, que passou de 1,12 hectares para 6,94 hectares nos respectivos períodos.

Nunes et al. (2015) fizeram um estudo de caso a respeito do impacto do Agroamigo sobre a apicultura no Território do Sertão do Apodi - RN. A pesquisa foi realizada com dados primários, colhidos em 40 casas de mel, dois entrepostos e duas cooperativas, como também dados secundários, buscando analisar a produção, geração de valor e comercialização do mel no período de 2005 a 2015, coincidindo com o período de atuação do Agroamigo. Analisando o volume de contratos financiados com o Agroamigo, notou-se uma grande evolução nessa região em função de uma melhoria na qualidade do atendimento e também de uma redução dos custos para se obter o crédito, impactando em maior desenvolvimento dessas classes beneficiadas. O trabalho constatou que o programa tem concentrado os investimentos em cadeias tradicionais, como a pecuária, enquanto tem contribuído em pequena escala em cadeias novas, como a apicultura. A permanência do viés setorial da pecuária do PRONAF B também foi verificada por Aquino e Bastos (2015), que realizaram estudo na região Nordeste, utilizando dados secundários.

Duarte, Costa e Araujo (2017) analisaram os efeitos do Agroamigo na redução do nível de pobreza no Nordeste brasileiro para o período de 2005 a 2012, haja vista que o microcrédito se tornou uma das ferramentas que agem no combate à pobreza. Para se estimar os determinantes da pobreza, empregaram-se dados em painel por meio dos modelos de efeitos fixos e aleatórios. Os resultados mostraram que há uma relação inversa entre o número de beneficiários do Agroamigo e o nível de pobreza nessa região, sendo que, para um acréscimo de $1 \%$ na quantidade de beneficiários, há uma redução de $0,034 \%$ do nível de pobreza, corroborando a contribuição do programa na redução da pobreza dos seus beneficiários. 
Duarte et al. (2018) buscaram verificar o efeito do Agroamigo na produção e produtividade por trabalhador dos agricultores familiares beneficiados em 13 municípios cearenses, que fazem parte do Cariri Central (dentre eles, o município de Jardim, objeto de estudo deste trabalho) no período de novembro a dezembro de 2016 mediante o método de efeitos heterogêneos de tratamento. Os resultados indicaram que há efeito positivo e significante sobre o valor bruto da produção dos pequenos produtores que apresentam piores condições socioeconômicas. Quanto à produtividade por trabalhador, verificou-se que há efeito apenas para os que possuem maior probabilidade ao benefício.

Embora os efeitos do Agroamigo tenham despertado o interesse de diversas pesquisas, não se encontraram, nessa literatura especializada, estudos que analisaram os efeitos deste programa sobre a sustentabilidade social, econômica, ambiental e institucional dos agricultores familiares. Tais efeitos são tratados neste trabalho, contribuindo com a literatura.

\section{Metodologia}

\section{Caracterização da área de estudo}

Este estudo foi realizado por meio da coleta de dados com beneficiários do programa de microcrédito rural Agroamigo e também com os não beneficiários desse programa no município cearense de Jardim. Entre os municípios da Região Metropolitana do Cariri (RMC)3 , Jardim é o que possui maior proporção da população residindo na zona rural. Segundo dados do IBGE (2016), em 2010, dos 26.688 habitantes, 17.694 residiam no campo, o que corresponde a um percentual de 63,30\%. Apesar de sua maior parte da população residir na zona rural, $77,81 \%$ de sua economia baseia-se na prestação de serviços, tendo como contribuição 19,38\% na agropecuária e 2,81\% na indústria (IPECE, 2016). Como a atuação do Agroamigo é voltada em grande escala para o meio rural, justifica-se a escolha desse município como área de estudo.

O município de Jardim localiza-se no extremo sul do estado do Ceará, microrregião do Cariri. Possui uma área da unidade territorial de $552,4 \mathrm{~km}^{2}$ e situa-se a uma distância de aproximadamente 435 km, em linha reta, de Fortaleza, a capital do Estado.

\section{Natureza dos dados e tamanho da amostra}

A natureza dos dados foi obtida por meio de informações primárias, adquiridas mediante a aplicação de questionários de fevereiro a abril de 2018, com uma amostra de produtores rurais beneficiários e não beneficiários do Programa de Microcrédito Agroamigo do município de Jardim, Ceará. Essa coleta de dados contou com auxílio de líderes comunitários na localização dos entrevistados. A aplicação dos questionários com tais agricultores familiares só foi iniciada após o cumprimento de todos os trâmites e aprovação pelo Comitê de Ética em Pesquisa sob CAAE 83104018.6.0000.5055.

Para determinação da amostra, empregou-se a fórmula sugerida por Fonseca e Martins (2010) para populações finitas por meio da amostragem aleatória simples:

${ }^{3} \mathrm{~A}$ RMC é composta pelos seguintes municípios: Juazeiro do Norte, Crato, Barbalha, Jardim, Missão Velha, Caririaçu, Farias Brito, Nova Olinda e Santana do Cariri (MORAIS; MACEDO, 2014). 


$$
n=\frac{Z^{2} \cdot p \cdot q \cdot N}{d^{2} \cdot(N-1)+Z^{2} \cdot p \cdot q} \text { (1), em que n refere-se ao tamanho da amostra; } z \text {, abscissa da normal }
$$

padrão; p, estimativa da proporção da característica pesquisada no universo; $q=1-p ; N$, número total de beneficiários do Programa Agroamigo; e d corresponde ao erro amostral.

De acordo com o Banco do Nordeste, o município de Jardim possuía 1.947 beneficiários do Programa Agroamigo em abril de 2017 e, segundo a EMATERCE (2018), há 5.103 declarações ativas de aptidão ao PRONAF (DAP ativas) no município de Jardim, distribuídas em 94 localidades. Para efeito de aplicação de questionários com os agricultores beneficiários do Agroamigo e não beneficiários, foram consideradas as dez localidades com maior número de cadastros emitidos, de forma que o número de questionários aplicados em cada uma dessas localidades foi proporcional ao número de agricultores familiares. Desse total de agricultores familiares, conforme descrito, 1.947 são beneficiários do Agroamigo e o restante é não beneficiário.

Com base nesses dados e admitindo um erro de estimação de 10\% (d=0,10), abscissa da normal padrão $Z=1,64$, ao nível de confiança de $90 \%$ e $\mathrm{p}=\mathrm{q}=0,5$ (na hipótese de se admitir o maior tamanho da amostra, já que não se conhecem as proporções estudadas), resultou em um tamanho da amostra igual a 66 beneficiários ${ }^{4}$.

Para se mensurar a amostra de não beneficiários do programa Agroamigo nesse município, replicando a fórmula (1) e considerando que o município tenha 3.156 agricultores familiares não beneficiários desse programa, e admitindo um erro de estimação de $10 \%(\mathrm{~d}=0,10)$, abscissa da normal padrão $Z=1,64$, ao nível de confiança de $90 \%$ e $p=q=0,5$, obteve-se um tamanho da amostra igual a 66 não beneficiários 5 .

\section{Métodos analíticos}

Para determinar o índice de sustentabilidade social, econômica, ambiental e institucional dos agricultores beneficiários do Agroamigo e dos não beneficiários no município de Jardim, foram considerados os índices: Índice de Desenvolvimento Econômico Social (IDES), Índice de Capital Social (ICS), Índice Político-Institucional (IPI) e Índice de Desenvolvimento Ambiental (IDA). A escolha desses índices foi baseada nos estudos recentes realizados por Sousa, Melo e Sousa (2017); e Alves e Bastos (2011).

O IDES pode assumir valores de zero a um. Com base na literatura citada na revisão bibliográfica, levou-se em conta que se o IDES apresentar valor de zero a 0,5, classifica-se como baixo nível de desenvolvimento econômico e social; se estiver valor entre 0,5 e 0,8 , considera-se como médio e para valores acima de 0,8 , alto nível de desenvolvimento econômico e social. Os demais índices seguem o mesmo critério de classificação.

\footnotetext{
${ }^{4}$ Distribuído em 8 questionários em Serra Gravata; 7 cada em Engenho D'água, Fazenda Nova, Serra Boca da Mata, Serra Olho D'água, Serra Horizonte e Serra Areias; 6 em Corrente; 5 cada em Lagoa do Alto e Serra Brejinho.

${ }^{5}$ Mesma distribuição adotada no grupo dos beneficiários.
} 
Em termos algébricos, o Índice de Desenvolvimento Econômico Social (IDES ) e a contribuição de cada indicador na composição do IDES são expressas, respectivamente, pelas equações (2) e (3):

$$
\text { IDES }=\frac{1}{n} \sum_{j=1}^{n}\left[\frac{\sum_{i=1}^{m} E_{i j} P_{i j}}{\sum_{i=1}^{m} E_{\max _{i}} P_{\max _{i}}}\right]
$$

$$
C_{i}=\frac{\sum_{i=1}^{m} E_{i j} P_{i j}}{n\left(\sum_{i=1}^{m} E_{\max _{i}} P_{\max _{i}}\right)} \text { (3), }
$$

em que: $P_{i j}$ corresponde ao peso do i-ésimo indicador, obtido pelo j-ésimo agricultor; $P_{\max _{i}}$, peso máximo do i-ésimo indicador; $E_{i j}$, escore do i-ésimo indicador.

O IDES considera os seguintes indicadores: i) saúde; ii) educação; iii) habitação; e econômico. A seleção desses indicadores foi baseada na literatura. Embora o estudo de Sousa, Melo e Sousa (2017) tenha incluído outros indicadores para captar o IDES, como condições sanitárias e higiene; alimentação; e lazer, tais indicadores não foram considerados neste estudo, pois, conforme Cruz (2012), alimentação e lazer não foram apontados como relevantes na ótica dos beneficiários do programa Agroamigo. A esse respeito, Maciel et al. (2009) constataram que condições sanitárias e higiene e lazer não são determinantes que influenciaram o índice de qualidade de vida dos beneficiários desse programa.

Quanto à saúde, consideraram questões que implicam na forma de atendimento fornecida pelo Sistema Único de Saúde (SUS) e o acesso aos medicamentos. Em relação à forma de atendimento utilizada pelas familias, foram adotados escores que variam de zero a dois, sendo (0) referente à ausência total de atendimento médico hospitalar, (1) se for atendido apenas com urgência ou emergência e (2) refere-se ao atendimento regular e sempre que necessário. Quanto ao acesso aos medicamentos, foram averiguados se os mesmos não possuem nenhum acesso aos medicamentos ofertados pelo SUS, cujo escore atribuído foi (0); se obtém acesso parcialmente (1) ou se tem acesso a todos os medicamentos necessários (2).

Para o indicador educação, foram considerados o grau de escolaridade dos entrevistados e a existência ou não de escolas na comunidade em que residem ou em regiões próximas. Admitindo o nível fundamental incompleto (0), fundamental completo (1), nível médio incompleto (2) e ensino médio completo (3). Em relação à existência ou não de escola na comunidade ou em regiões próximas, foram adotados escores (0) para ausência de escolas e (1) para existência de escolas.

Em se tratando de habitação, analisaram-se a condição do domicilio, o tipo de construção das residências e a iluminação utilizada nessas moradias. Na condição do domicílio, se o domínio for não próprio, o escore foi (0) e se for casa própria, escore (1). Quanto ao tipo de moradia, se for casa de taipa, escore (0); casa de tijolo, sem reboco e piso de cimento, escore (1); e se for casa de tijolo, com reboco e piso de cerâmica, escore (2). Sobre a iluminação utilizada nas casas dos entrevistados, se não tiver energia elétrica, o escore foi (0) e se tiver energia elétrica, o escore foi (1).

A respeito do indicador econômico, foram consideradas as variáveis que remetem à origem da renda e a posse de bens duráveis. Se a maior parte da renda (>50\%) não for oriunda da atividade rural, adotou-se escore (0) e se a maior parte da renda ( $>50 \%$ ) for advinda do meio rural, o escore foi (1). Sobre a posse de bens duráveis, foram analisados três grupos, sendo o primeiro formado por: rádio, ferro, 
liquidificador, bicicleta; o segundo por: televisão, fogão a gás, equipamento de som, celular; e o terceiro por: geladeira, antena parabólica, computador, motocicleta, automóvel. Se o agricultor familiar não possuir nenhum dos bens citados, atribuiu-se escore (0); se possuir pelo menos um dos bens do primeiro grupo, adotou escore (1); se possuir pelo menos um dos bens do primeiro e segundo grupos considerou escore (2); e, por fim, se possuir pelo menos um dos bens do primeiro, segundo e terceiro grupos, atribuiu-se escore (3).

As variáveis consideradas no ICS visam identificar se o mesmo participa de alguma organização, se frequenta as reuniões da associação, se são apresentadas sugestões nas reuniões, e se desempenhou algum cargo ou teve algum tipo de responsabilidade no funcionamento de alguma entidade social em sua localidade. Para todas as variáveis citadas, foram considerados o escore (1) para respostas positivas e escore (0) para negativas, atingindo o escore máximo (4) àqueles que responderem positivamente a todos os questionamentos.

Na formação do Índice de Desenvolvimento Ambiental (IDA), foram englobadas as variáveis que mostram se foi realizada práticas de conservação na propriedade; se existe alguma área de reserva de mata nativa na propriedade; se foi feita a rotação de culturas; e se está cadastrado no Cadastro Ambiental Rural - CAR. Para todas as variáveis citadas, foram considerados o escore (1) para respostas positivas e escore (0) para respostas negativas, atingindo o escore máximo (4) àqueles que responderem positivamente a todos os questionamentos.

Quanto ao IPI, buscou-se saber se é fornecido ou não assistência técnica pública, benefício de instituição pública, e produtos e serviços oferecidos pela Secretaria de Agricultura Municipal ou Estadual, assim como se já participou ou não de algum curso de capacitação e treinamento fornecido pelo poder público e/ou de algum evento promovido pelo poder público. Para todas as variáveis citadas, foram considerados o escore (1) para respostas positivas e escore (0) para respostas negativas, atingindo o escore máximo (4) àqueles que responderem positivamente a todos os questionamentos.

\section{Resultados e discussão}

\section{Índice de Desenvolvimento Econômico e Social (IDES)}

Os valores relativos e absolutos referentes às participações dos beneficiários e não beneficiários do Agroamigo nos indicadores do IDES estão expostos na Tabela 1. Dos indicadores que compõem o IDES, Habitação e Econômico, juntos representam 58,06\% de contribuição dos beneficiários, com destaque para o indicador Habitação que atingiu 29,62\%. O indicador Habitação também se destaca com maior participação nos estudos de Alves e Bastos (2011) e Sousa, Melo e Sousa (2017). O indicador Educação, por sua vez, obteve a menor contribuição para o IDES alertando-se para questões relevantes como grau de escolaridade. Analisando o grupo dos não beneficiários, os resultados são semelhantes, uma vez que o indicador Habitação é o que mais contribui para o IDES, com parcela de 29,07\%, ao passo que o indicador Educação representa aquele que menos contribui, com apenas 19,09\%. 
Tabela 1 - Participação absoluta e relativa dos agricultores familiares beneficiários e não beneficiários do Agroamigo, segundo os indicadores que compõem o IDES, em Jardim, Ceará, 2018.

\begin{tabular}{|c|c|c|c|c|c|c|}
\hline \multirow{2}{*}{$\begin{array}{l}\text { Indicadores } \\
\text { do IDES }\end{array}$} & \multicolumn{3}{|c|}{ Beneficiários } & \multicolumn{3}{|c|}{ Não beneficiários } \\
\hline & $\begin{array}{c}\text { Valores } \\
\text { absolutos }\end{array}$ & $\begin{array}{c}\text { Valores } \\
\text { relativos }\end{array}$ & IDES & $\begin{array}{c}\text { Valores } \\
\text { absolutos }\end{array}$ & $\begin{array}{c}\text { Valores } \\
\text { relativos }\end{array}$ & IDES \\
\hline Saúde & 0,1884 & 26,0813 & 0,7538 & 0,1847 & 24,6523 & 0,7386 \\
\hline Educação & 0,1146 & 15,8585 & 0,4583 & 0,1430 & 19,0898 & 0,5720 \\
\hline Habitação & 0,2140 & 29,6199 & 0,8561 & 0,2178 & 29,0771 & 0,8712 \\
\hline Econômico & 0,2055 & 28,4404 & 0,8220 & 0,2036 & 27,1808 & 0,8144 \\
\hline Total & 0,7225 & 100,0000 & 0,7225 & 0,7491 & 100,0000 & 0,7491 \\
\hline
\end{tabular}

Fonte: Elaborada com base nos dados da pesquisa (2018).

Seguindo a classificação definida na metodologia e replicando para os demais índices, o Gráfico 1 aponta que a maior parte de agricultores familiares entrevistados nos dois grupos registrou um nível médio de desenvolvimento econômico e social, com destaque para os beneficiários, que corresponderam 62,02\%, enquanto uma pequena parcela dos entrevistados registrou baixo nível. Esse resultado que indica a maior participação relativa de agricultores familiares com nível intermediário de desenvolvimento econômico e social também foi evidenciado no estudo desenvolvido por Sousa, Melo e Sousa (2017) para os agricultores familiares do município de Barro, CE.

Gráfico 1 - Frequência relativa do IDES dos beneficiários e não beneficiários do Agroamigo em Jardim, Ceará, 2018.

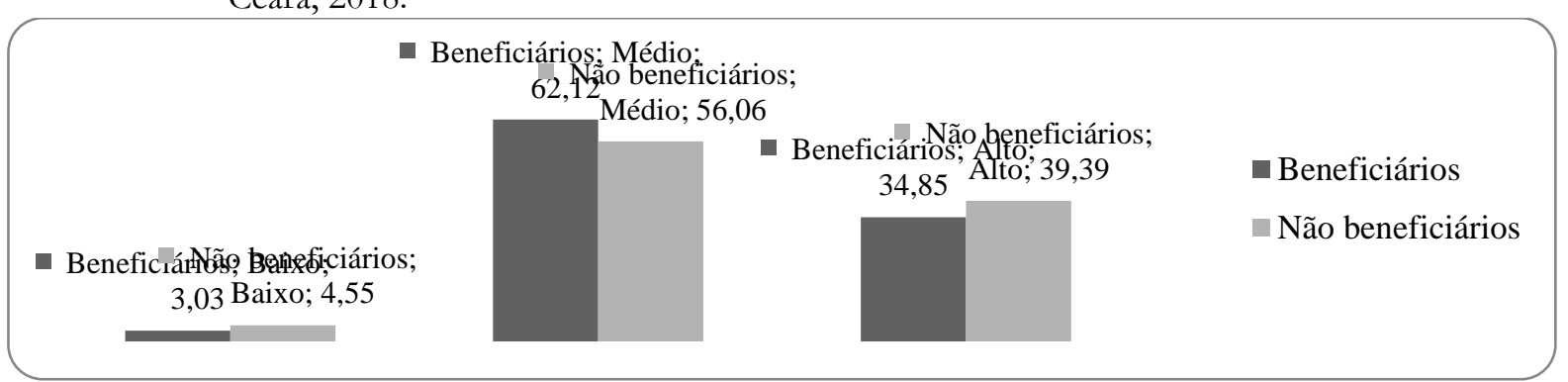

Fonte: Elaborado com base nos dados da pesquisa (2018).

\section{Índice de Capital Social}

Dentre os quatro indicadores que formam o ICS expostos na Tabela 2, o que mais contribuiu no grupo dos beneficiários foi a participação em alguma organização social, como associação e cooperativa, com 32,82\%. Em contrapartida, o que menos contribuiu foi o desempenho de cargo em alguma dessas entidades sociais com 9,92\%, assim como no grupo dos não beneficiários com 10,37\%. Essa evidência também é verificada nos estudos de Alves e Bastos (2011) e Sousa, Melo e Sousa (2017). No grupo dos não beneficiários, o indicador que mais contribui é a participação em reuniões da associação com 31,13\%. 
Tabela 2 - Participação absoluta e relativa dos agricultores familiares beneficiários e não beneficiários do Agroamigo, segundo os indicadores que compõem o ICS, em Jardim, Ceará, 2018.

\begin{tabular}{|c|c|c|c|c|c|c|}
\hline \multirow[t]{2}{*}{ Indicadores do ICS } & \multicolumn{3}{|c|}{ Beneficiários } & \multicolumn{3}{|c|}{ Não beneficiários } \\
\hline & $\begin{array}{c}\text { Valores } \\
\text { absolutos }\end{array}$ & $\begin{array}{l}\text { Valores } \\
\text { relativos }\end{array}$ & ICS & $\begin{array}{l}\text { Valores } \\
\text { absolutos }\end{array}$ & $\begin{array}{l}\text { Valores } \\
\text { relativos }\end{array}$ & ICS \\
\hline $\begin{array}{lc}\text { Participa em } & \text { alguma } \\
\text { organização social }\end{array}$ & 0,1629 & 32,8244 & 0,6515 & 0,1174 & 29,2453 & 0,4697 \\
\hline $\begin{array}{l}\text { Frequenta } \\
\text { associação }\end{array}$ & 0,1477 & 29,7710 & 0,5909 & 0,1250 & 31,1321 & 0,5000 \\
\hline $\begin{array}{l}\text { Apresentação de sugestões } \\
\text { nas reuniões }\end{array}$ & 0,1364 & 27,4809 & 0,5455 & 0,1174 & 29,2453 & 0,4697 \\
\hline $\begin{array}{l}\text { Desempenho de cargo em } \\
\text { alguma entidade social }\end{array}$ & 0,0492 & 9,9237 & 0,1970 & 0,0417 & 10,3774 & 0,1667 \\
\hline Total & 0,4962 & 100,0000 & 0,4962 & 0,4015 & 100,0000 & 0,4015 \\
\hline
\end{tabular}

Fonte: Elaborada com base nos dados da pesquisa (2018).

A partir desses dados, deduz-se que a maior parte dos beneficiários participa de alguma organização social, mas uma pequena parte não frequenta as reuniões, enquanto os não beneficiários contam com um percentual majoritário de presença nas reuniões.

De acordo com o Gráfico 2, a maior parte dos entrevistados dos dois grupos possui um ICS baixo, com maior participação para os não beneficiários que corresponde a 54,55\%, enquanto a menor parcela dos entrevistados se enquadra com índice alto, excedendo para os beneficiários, que representa 16,67\%. Tal resultado sinaliza que os beneficiários do Agroamigo obtiveram ICS melhor do que os não beneficiários.

Gráfico 2 - Frequência relativa do ICS dos beneficiários e não beneficiários do Agroamigo em Jardim, Ceará, 2018.

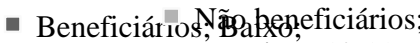

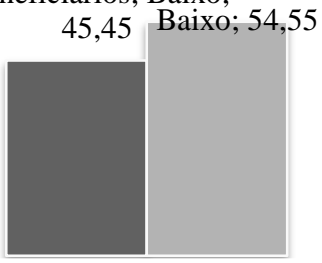

- Beneficiários; Médio;

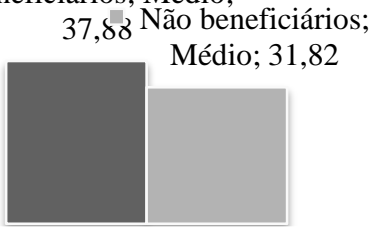

- Beneficiários: Beneficiciários 16,67 Nãedoenzefíciários

Fonte: Elaborado com base nos dados da pesquisa (2018)

\section{Índice Político Institucional}

Este índice investiga se os produtores rurais recebem algum tipo de assistência pública, bem como produtos e benefícios, como, por exemplo, tratores e equipamentos. A partir da Tabela 3, é notória a relevância do indicador que trata sobre benefícios auferidos de instituições públicas pelos produtores em ambos os grupos, com ênfase para os não beneficiários com 39,60\%. 
Tabela 3 - Participação absoluta e relativa dos agricultores familiares beneficiários e não beneficiários do Agroamigo, segundo os indicadores que compõem o IPI, em Jardim, Ceará, 2018.

\begin{tabular}{|c|c|c|c|c|c|c|}
\hline \multirow[t]{2}{*}{ Indicadores do IPI } & \multicolumn{3}{|c|}{ Beneficiários } & \multicolumn{3}{|c|}{ Não beneficiários } \\
\hline & $\begin{array}{l}\text { Valores } \\
\text { absolutos }\end{array}$ & $\begin{array}{l}\text { Valores } \\
\text { relativos }\end{array}$ & IPI & $\begin{array}{c}\text { Valores } \\
\text { absolutos }\end{array}$ & $\begin{array}{l}\text { Valores } \\
\text { relativos }\end{array}$ & IPI \\
\hline $\begin{array}{l}\text { Recebe assistência técnica } \\
\text { pública }\end{array}$ & 0,1477 & 26,1745 & 0,5909 & 0,0795 & 20,7921 & 0,3182 \\
\hline $\begin{array}{l}\text { Recebe outro tipo de benefício } \\
\text { de instituição pública }\end{array}$ & 0,2083 & 36,9128 & 0,8333 & 0,1515 & 39,6040 & 0,6061 \\
\hline $\begin{array}{l}\text { Recebe produtos e serviços } \\
\text { oferecidos pela Secretaria de } \\
\text { Agricultura Municipal ou } \\
\text { Estadual }\end{array}$ & 0,1477 & 26,1745 & 0,5909 & 0,0947 & 24,7525 & 0,3788 \\
\hline $\begin{array}{llr}\text { Participa } & \text { de alguma } \\
\text { capacitação, evento } & \text { ou } \\
\text { treinamento fornecido pelo } \\
\text { poder público }\end{array}$ & 0,0606 & 10,7383 & 0,2424 & 0,0568 & 14,8515 & 0,2273 \\
\hline Total & 0,5644 & 100,000 & 0,5644 & 0,3826 & 100,000 & 0,3826 \\
\hline
\end{tabular}

Fonte: Elaborada com base nos dados da pesquisa (2018).

O indicador que contribuiu menos para os dois grupos foi a participação em capacitação, evento ou treinamento ofertado pelo setor público, sendo a maior parte correspondente aos não beneficiários com 14,85\%. Isso denota que os produtores rurais familiares de Jardim, Ceará, em geral, são carentes de políticas públicas voltadas para o desenvolvimento rural local.

Percebe-se pelo Gráfico 3 que a maioria dos entrevistados dos dois grupos possui Índice Político Institucional (IPI) baixo, com percentual maior para os não beneficiários, correspondendo $71,21 \%$, ao passo que uma pequena parte dos dois grupos possuem índice considerável alto, sendo os beneficiários com maior percentual, representando $13,64 \%$.

Gráfico 3 - Frequência relativa do IPI dos beneficiários e não beneficiários do Agroamigo em Jardim, Ceará, 2018.

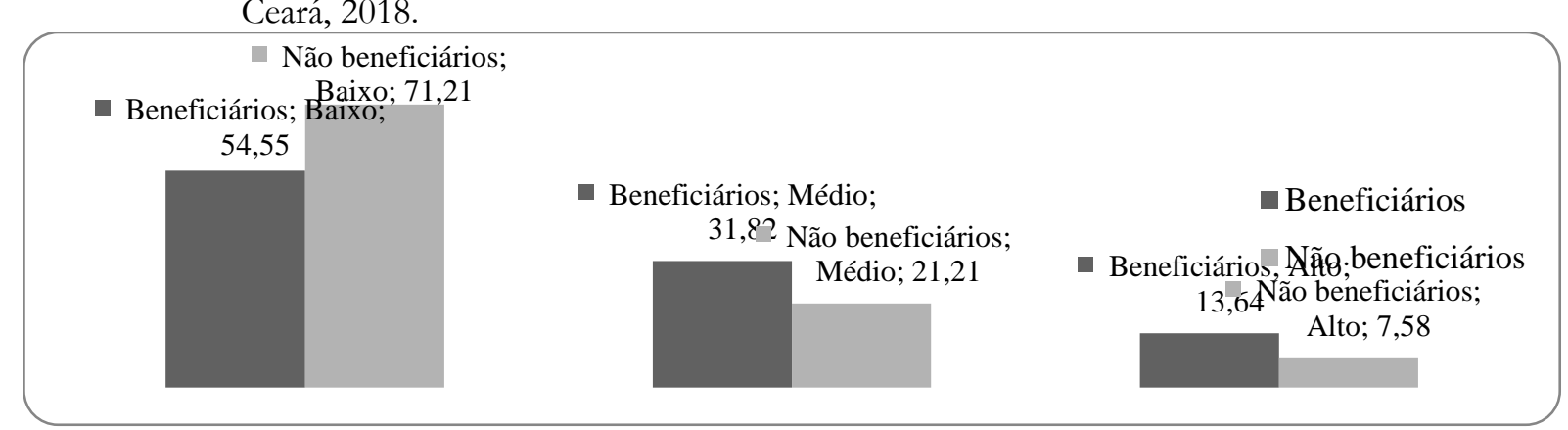

Fonte: Elaborado com base nos dados da pesquisa (2018).

\section{Índice de Desenvolvimento Ambiental}

O Índice de Desenvolvimento Ambiental remete a questões sobre o uso da terra e forma de plantio adotada pelos produtores entrevistados, averiguando se há ou não realização de práticas de conservação ambiental. 
Como se percebe pela Tabela 4, dos quatro indicadores do IDA, o mais expressivo para os beneficiários foi a realização de práticas de conservação ambiental, correspondendo a 39,76\%, assim como para os não beneficiários, em que este indicador representou 42,55\%. A prática de conservação ambiental está mais presente no grupo dos não beneficiários em função da especificidade da atividade, já que a maioria trabalha na agricultura, ao passo que os beneficiários possuem uma diversidade, atuando em larga escala na pecuária. Tais resultados estão de acordo com os encontrados por Nunes et al. (2015) e Aquino e Bastos (2015). Essa diversificação das atividades realizadas pelos beneficiários pode contribuir para enfrentar problemas de seca na região, conter o êxodo rural, influenciando na sustentabilidade.

Tabela 4 - Participação absoluta e relativa dos agricultores familiares beneficiários e não beneficiários do Agroamigo, segundo os indicadores que compõem o IDA, em Jardim, Ceará, 2018.

\begin{tabular}{|c|c|c|c|c|c|c|}
\hline \multirow[t]{2}{*}{ Indicadores do IDA } & \multicolumn{3}{|c|}{ Beneficiários } & \multicolumn{3}{|c|}{ Não beneficiários } \\
\hline & $\begin{array}{c}\text { Valores } \\
\text { absolutos }\end{array}$ & $\begin{array}{c}\text { Valores } \\
\text { relativos }\end{array}$ & IDA & $\begin{array}{c}\text { Valores } \\
\text { absolutos }\end{array}$ & $\begin{array}{l}\text { Valores } \\
\text { relativos }\end{array}$ & IDA \\
\hline $\begin{array}{l}\text { Realização de práticas de } \\
\text { conservação } \\
\text { propriedade }\end{array}$ & 0,1250 & 39,7590 & 0,5000 & 0,1515 & 42,5532 & 0,6061 \\
\hline $\begin{array}{l}\text { Possui área de reserva de } \\
\text { mata nativa na } \\
\text { propriedade }\end{array}$ & 0,0947 & 30,1205 & 0,3788 & 0,0909 & 25,5319 & 0,3636 \\
\hline $\begin{array}{l}\text { Realização de rotação de } \\
\text { culturas }\end{array}$ & 0,0455 & 14,4578 & 0,1818 & 0,0492 & 13,8298 & 0,1970 \\
\hline $\begin{array}{lr}\text { Possui } & \text { registro no } \\
\text { Cadastro } & \text { Ambiental } \\
\text { Rural } & \\
\end{array}$ & 0,0492 & 15,6627 & 0,1970 & 0,0644 & 18,0851 & 0,2576 \\
\hline Total & 0,3144 & 100,0000 & 0,3144 & 0,3561 & 100,0000 & 0,3561 \\
\hline
\end{tabular}

Fonte: Elaborada com base nos dados da pesquisa (2018).

O indicador que teve menor parcela de contribuição foi a promoção de rotação de culturas, com participação mínima dos beneficiários, correspondendo 14,46\%. Os motivos apresentados pelos entrevistados dos dois grupos foram a deficiência na fertilidade do solo e o clima que o tornam restritas à produção de algumas culturas.

O Gráfico 4 ilustra que, de forma geral, os produtores rurais possuem baixo nível de desenvolvimento ambiental, sendo os beneficiários responsáveis pela maior parcela, correspondente a $78,79 \%$, enquanto apenas uma pequena parte classifica-se com nível alto, sendo a maioria dos não beneficiários representados por 10,61\%. 
Gráfico 4 - Frequência relativa do IDA dos beneficiários e não beneficiários do Agroamigo em Jardim, Ceará, 2018.

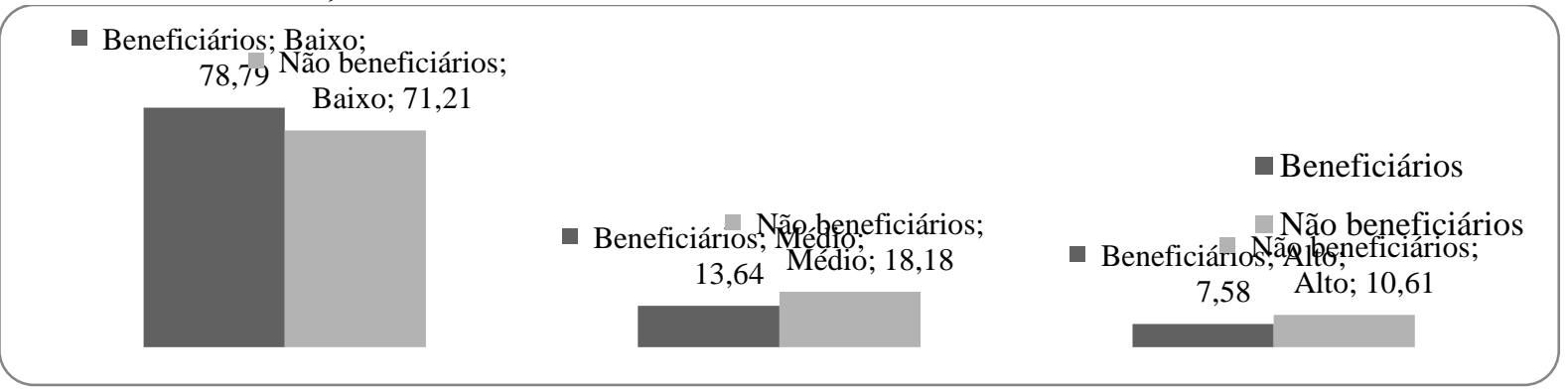

Fonte: Elaborado com base nos dados da pesquisa (2018).

\section{Índice de Sustentabilidade}

O índice de sustentabilidade é calculado a partir da média dos indicadores utilizados. De acordo com a Tabela 5, dos indicadores que compõem o Índice de Sustentabilidade, o que teve mais representatividade foi o IDES, com 67,76\% para os beneficiários e 72,44\% para os não beneficiários. Já o indicador Ambiental foi o que menos contribuiu para os dois grupos, representando apenas 7,37\% para os beneficiários e 8,61\% para os não beneficiários.

Tabela 5 - Participação absoluta e relativa dos agricultores familiares beneficiários e não beneficiários do Agroamigo, segundo os indicadores que compõem o IS, em Jardim, Ceará, 2018.

\begin{tabular}{l|cc|cc}
\hline \multirow{2}{*}{ Indicadores do IS } & \multicolumn{2}{|c|}{ Beneficiários } & \multicolumn{2}{c}{ Não beneficiários } \\
\cline { 2 - 5 } & $\begin{array}{c}\text { Valores } \\
\text { absolutos }\end{array}$ & $\begin{array}{c}\text { Valores } \\
\text { relativos }\end{array}$ & $\begin{array}{c}\text { Valores } \\
\text { absolutos }\end{array}$ & $\begin{array}{c}\text { Valores } \\
\text { relativos }\end{array}$ \\
\hline Desenvolvimento Econômico e Social & 0,41 & 67,76 & 0,43 & 72,44 \\
Capital Social & 0,07 & 11,63 & 0,06 & 9,71 \\
Político Institucional & 0,08 & 13,23 & 0,05 & 9,25 \\
Ambiental & 0,04 & 7,37 & 0,05 & 8,61 \\
\hline IS & 0,61 & 100,00 & 0,59 & 100,00 \\
\hline
\end{tabular}

Fonte: Elaborada com base nos dados da pesquisa (2018).

O Gráfico 5 mostra o Índice de Sustentabilidade do produtor rural familiar de Jardim, Ceará. Conforme se observa, classifica-se, em maior parte, como médio, sendo os não beneficiários responsáveis por $65,15 \%$, enquanto os beneficiários com $63,64 \%$. Existe ainda uma minoria que se configura como grau de sustentabilidade alto, com destaque para os beneficiários que atingiram 9,09\%.

Gráfico 5 - Frequência relativa do IS dos beneficiários e não beneficiários do Agroamigo em Jardim, Ceará, 2018.

- Beneficiários; Bãa beneficiciários;

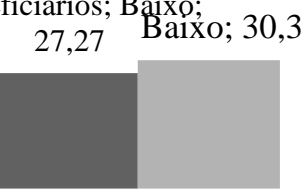

- Beneficiários, Nẽelibẹneficiários;

63,64 Médio; 65,15

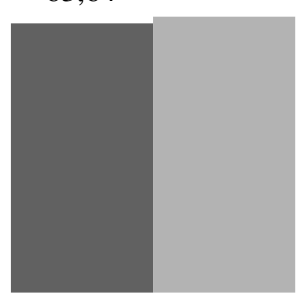

- Beneficiários

Não beneficiários

- BeneficiáriłsãAltteneficiários; 9,09

Alto; 4,55

Fonte: Elaborado com base nos dados da pesquisa (2018). 


\section{Considerações finais}

A criação do PRONAF B foi uma das medidas para combater o êxodo rural, por meio de incentivos àqueles produtores rurais socialmente mais vulneráveis. Como forma de aperfeiçoamento, surge, em 2005, o Agroamigo do Banco do Nordeste que vem tornando esta linha de crédito cada vez mais acessível, contribuindo com a geração de emprego e renda, redução dos níveis de pobreza, igualdade de gênero e, em geral, uma melhoria na qualidade de vida. Os principais efeitos do Agroamigo sobre a qualidade de vida dos seus beneficiários apontados pela literatura estão ligados às condições de moradia, educação e saúde.

No município de Jardim, Ceará, mediante a pesquisa de campo com agricultores familiares, verifica-se que os beneficiários possuem uma maior diversidade na produção, explorando atividades rurais, como a criação de animais em larga escala, plantio de hortaliças e agricultura de sequeiro e, em alguns casos, até o artesanato. Ao passo que os não beneficiários, em maior parte, concentram sua produção na agricultura de sequeiro. Isso ocorre em função dos não beneficiários serem resistentes às novas atividades rurais e na maior parte das vezes cultivam da forma que aprenderam com os seus pais. Essa diversificação das atividades realizadas pelos beneficiários pode contribuir para enfrentar problemas de seca na região, conter o êxodo rural, influenciando na sustentabilidade.

Analisando os indicadores que constitui o Índice de Sustentabilidade, constata-se que o Índice de Desenvolvimento Econômico e Social teve maior representatividade. Dos indicadores do IDES, os que apresentaram maiores contribuições tanto para os beneficiários quanto para os não beneficiários foram Habitação e Econômico com ênfase para Habitação. Por outro lado, o indicador Educação é o que merece mais atenção, pois, para os dois grupos, registraram as menores contribuições. Dentre os objetivos propostos pelo Agroamigo, pode-se destacar que busca melhorar a qualidade de vida da população rural. Como educação faz parte da qualidade de vida, o programa reflete diretamente nesse indicador, porém deve ser complementado com outros programas específicos para essa demanda.

Os principais resultados do grupo dos beneficiários estão vinculados ao Índice de Capital Social, evidenciando a preocupação com o bem-estar coletivo e ao Índice Político Institucional enfatizando o maior apoio público no desenvolvimento das suas atividades.

O Índice Ambiental é o que traz as maiores preocupações, apesar de os não beneficiários obterem uma ligeira vantagem sobre os não beneficiários. Verifica-se que a situação ambiental nos dois grupos é crítica, em função de a maior parte dos produtores rurais não atentar para preservação do meio ambiente ou até mesmo da regularização do seu imóvel rural junto aos órgãos competentes. Embora uma melhoria introduzida pelo Agroamigo seja conscientizar os agricultores quanto à necessidade de exploração sustentável do meio ambiente, a atuação de programas que se preocupe com o meio ambiente reveste-se de importância.

A partir da pesquisa de campo, surgiram dificuldades como a identificação dos beneficiários das linhas de crédito "Crescer" e "Mais", ambas vinculadas ao Programa Agroamigo, em função de que a quantidade dos produtores que fazem parte do "Agroamigo Mais" ser inexpressiva, tornando sua 
localização muito mais difícil. Portanto, a pesquisa abre um leque de possibilidades de estudos para essa temática em diversos quesitos que podem ser aprofundados, inclusive desagregando o Agroamigo em suas linhas de créditos. Cabe mais adiante um estudo a respeito do "Agroamigo Sol”, em face de ser uma linha de crédito lançada há pouco tempo e que traz grandes vantagens para quem usufruir, além de ser uma forma de conscientização ambiental.

\section{Referências}

ABRAmOVAY, R. et al. Cinco anos de Agroamigo: retrato público e efeitos do programa. 2 ed. Fortaleza, 122p. Banco do Nordeste do Brasil, 2013.

ALVES, B. L.; BASTOS, R. P. Sustentabilidade em Silvânia (GO): o caso dos assentamentos rurais São Sebastião da Garganta e João de Deus. Revista de Economia e Sociologia Rural. Piracicaba, v. 49, n. 2, p. 419-448, 2011.

AQUINO, J. R.; BASTOS, F. Dez anos do Programa Agroamigo na Região Nordeste: evolução, resultados e limites para o fortalecimento da agricultura familiar. Revista Econômica do Nordeste, Fortaleza, v. 46, suplemento especial, p. 139-160, 2015.

BANCO CENTRAL DO BRASIL - BACEN. FAQ - Programa Nacional de Fortalecimento da

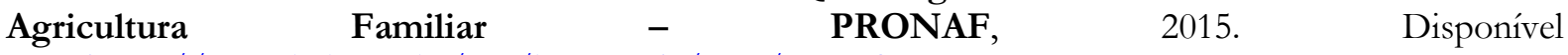
em: $<$ https://www.bcb.gov.br/pre/bc atende/port/pronaf.asp> Acesso em: 23 mar. 2017.

BANCO DO NORDESTE DO BRASIL - BNB. Programa de Microfinança do Nordeste: Relatório $2016 . \quad$ Disponível em: <http://www.banconordeste.gov.br/documents/22492/41207/RelatorioMicrocredito2016/47bbdf184b84-d33a-ab35-439ff932a4e2> Acesso em: 06 mai. 2017.

BANCO DO NORDESTE DO BRASIL- BNB. Microfinança - Agroamigo. 2019. Disponível em: $<$ https://www.bnb.gov.br/agroamigo > Acesso em: 17 set. 2019.

BANCO NACIONAL DE DESENVOLVIMENTO ECONÔMICO E SOCIAL - BNDES. Microcrédito no Brasil: histórico e legislação. 2016. Disponível em: $\quad<$ http://www.bndes.gov.br/wps/portal/site/home/conhecimento/noticias/noticia/microcreditobrasil>. Acesso em: 17 set. 2019.

CAVALCANTI, C. (org.) Desenvolvimento e natureza: estudo para uma sociedade sustentável. São Paulo: Cortez, 2003.

CRUZ, E. L. Inovação em serviço: o caso do Agroamigo e os seus efeitos sobre a qualidade de vida da clientela da praça de Caruaru - PE. Recife, PE, 2012, 142p. Dissertação (Mestrado Profissional em Gestão Empresarial) - Faculdade Boa Viagem, 2012.

DUARTE, S. P. S.; COSTA, E. M.; ARAÚJO, J. A. O microcrédito como estratégia de redução da pobreza no Nordeste Brasileiro: uma avaliação a partir do Programa Agroamigo. Revista Espacios. Caracas, v.38, n. 8, 2017.

DUARTE, S. P. S.; COSTA, E. M.; MARIANO, F. Z.; KHAN, A. S.; ARAÚJO, J. A. Efeitos heterogêneos do Programa Agroamigo sobre os pequenos produtores rurais. Revista Econômica do Nordeste, Fortaleza, v. 49, n. 2, p. 43-61, 2018.

FONSECA, J. S.; MARTINS, G. A. Curso de Estatística. São Paulo: Atlas, 2010. 
GONZALEZ, L.; PORTO, L.; DINIZ, E. H. Microcrédito produtivo no Brasil: histórico recente e condicionantes de desenvolvimento. Cadernos Gestão Pública e Cidadania. São Paulo, v. 22, n. 72, p. 193-213, maio/ago. 2017.

INSTITUTO BRASILEIRO DE GEOGRAFIA E ESTATÍSTICA- IBGE. Informações Completas de Jardim, Ceará. 2016. Disponível em: <http://cod.ibge.gov.br/2VXOY>. Acesso em: 04 jun. 2017.

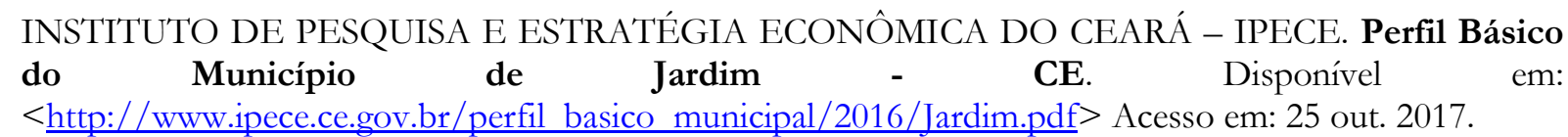

MACIEL, H. M; KHAN, A. S; MAYORGA, R. D; ALENCAR JUNIOR, J. S. O impacto do Programa de Microcrédito Rural (Agroamigo) na melhoria das condições das famílias beneficiadas no estado do Ceará: um estudo de caso. Revista Econômica do Nordeste. Fortaleza, v. 40, n. 3, p. 559-586, 2009.

MACIEL, I. S. R. Avaliação da metodologia do Agroamigo em Caucaia - CE. Fortaleza: Banco do Nordeste do Brasil, 2009. 272 p. (Série Dissertações e Teses, v. 17).

MORAIS, J. M. L.; MACEDO, F. C. Regiões Metropolitanas do Ceará: dispersão produtiva e concentração de serviços. Desenvolvimento Regional em Debate, v. 4, n. 2, p. 178-203, jul. / dez. 2014.

NASCIMENTO, R. C. Comunicação Oral. Jardim - CE: EMATERCE, 2017.

NERI, M. C. Microempresários nordestinos rurais e impactos do Agroamigo. Rio de Janeiro - RJ: Fundação Getúlio Vargas, 221 p., 2012.

NUNES, E. M.; LIMA, J. S. S.; TÔRRES, F. L.; FRANÇA, A. R. M.; MEDEIROS, L. S. O Agroamigo e a estruturação da agricultura familiar em Territórios da Cidadania: impactos na cadeia da apicultura no Sertão do Apodi - RN. Revista Econômica do Nordeste. Fortaleza, v. 46, suplemento especial, p. 105122, 2015.

ROSSETI, D. P. Agricultura familiar: aspectos motivadores do êxodo rural em Constantina - RS. Sarandi, RS, 2013, 84 p. Monografia (Graduação em Administração) - Universidade de Passo Fundo, 2013.

SACHS, I. Caminhos para o desenvolvimento sustentável. 3 ed. Rio de Janeiro: Garamond, 2008.

SANTOS, J. G.; CÂNDIDO, G. A. Sustentabilidade e agricultura familiar: um estudo de caso em uma associação de agricultores rurais. Revista de Gestão Social e Ambiental, v. 7, n. 1, p. 70-86, 2013.

SOUSA, W. D.; MELO, F. K. E.; SOUSA, E. P. Sustentabilidade da agricultura familiar no município de Barro - CE. Revista de Gestão e Sustentabilidade Ambiental. Florianópolis, v. 6, n. 2, p. 302 - 327, 2017.

VASCONCELOS, B. C. O Programa de Microcrédito Rural Agroamigo na busca pela melhoria na renda e nas condições de vida dos beneficiários no município de Rio Tinto - PB. 2014, 119p. Dissertação (Mestrado em Administração). Universidade Federal de Pernambuco, Recife - PE. 